\title{
DOCTORADO EN CIENCIAS DE LA ENFERMERÍA
}

El desarrollo disciplinar de la Enfermería hasta lograr el máximo Grado académico en España de manera regulada, comienza con la promulgación de los Reales Decretos 55 y 56/2005, donde se iguala la posibilidad de que todas las titulaciones que se encuentran en el espacio universitario, puedan si así lo desean obtener el grado de Doctor en su ámbito propio.

Esto no significa que las Enfermería no fuese Ciencia anteriormente. Solo que en España, al no tener regulación legal, el contexto científico siempre avanzaba por iniciativas privadas de determinados grupos o a través de Enfermeras que cursaban estudios superiores en el extranjero.

La legislación de 2005 es importante para muchas titulaciones, no solo para Enfermería y permite un progreso del conocimiento desde un ámbito propio, es decir aportar al trabajo enfermero los resultados de una investigación con impacto en la mejora del cuidado. Estos resultados se publican para que, la comunidad científica pueda enriquecerse y a su vez volverlos a aplicar con las aportaciones obtenidas; en definitiva, entrar en un proceso de mejora profesional que redunda sobre la calidad asistencial, en un ámbito propio.

La legislación más reciente se resume en el siguiente cuadro. 
Soporte legislativo del sistema Universitario español.

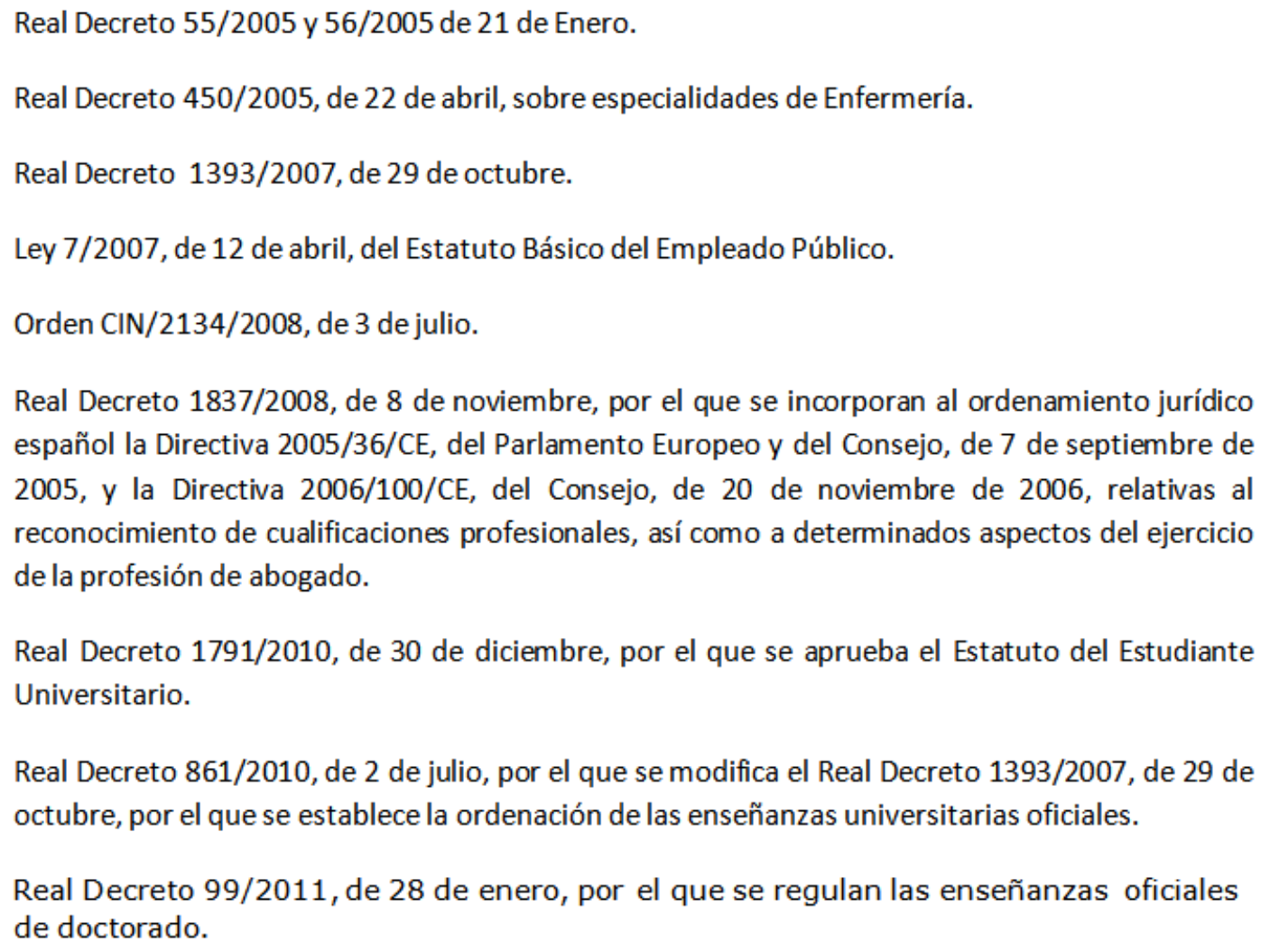

Real Decreto 1791/2010, de 30 de diciembre, por el que se aprueba el Estatuto del Estudiante Universitario.

Real Decreto 861/2010, de 2 de julio, por el que se modifica el Real Decreto 1393/2007, de 29 de octubre, por el que se establece la ordenación de las enseñanzas universitarias oficiales.

Real Decreto 99/2011, de 28 de enero, por el que se regulan las enseñanzas oficiales de doctorado.

Se observa que finalmente, la estructura de las titulaciones resultante es: Grado, Máster y Doctorado. Cada nivel tiene una característica:

\section{Grado:}

El primer ciclo de los estudios universitarios comprenderá enseñanzas básicas y de formación general, junto a otras orientadas a la preparación para el ejercicio de actividades de carácter profesional.

\section{Posgrado. Máster}

El segundo ciclo de los estudios universitarios estará dedicado a la formación avanzada, de carácter especializado o multidisciplinar, dirigida a una especialización académica o profesional o bien a promover la iniciación en tareas investigadoras. La superación del ciclo dará derecho a la obtención del título de Máster.

\section{Doctorado.}

El tercer ciclo de los estudios universitarios tendrá como finalidad la formación avanzada del estudiante en las técnicas de investigación, podrá 
incluir cursos, seminarios u otras actividades dirigidas a la formación investigadora e incluirá la elaboración y presentación de la correspondiente tesis doctoral, consistente en un trabajo original de investigación. La superación del ciclo dará derecho a la obtención del título de Doctor, que representa el nivel más elevado en la educación superior, acredita el más alto rango académico y faculta para la docencia y la investigación, de acuerdo con la legislación vigente.

Respecto al Doctorado, si bien hasta 2006 hay enfermeras que obtienen el máximo grado académico, la obtención del título como ya se ha comentado, se realizaba desde Universidades extranjeras o a través de otras disciplinas.

A partir de 2006 cuando existe, la posibilidad de doctorarse desde Enfermeria, se desata una autentica avalancha de profesionales que se quieren doctorar. Este aspecto es inusual en profesiones mas consolidadas.

Todas las personas que ejercen una profesión no deben tener el mismo grado académico. Esto daria lugar a una uniformidad extraña para el ejercicio de las competencias.

Lo que realmente es importante es la posibilidad de poder hacerlo y la libertad de eleccion intraprofesión.

El progreso que aporta el Doctorado, se logra cuando el trabajo clinico se nutre de una produccin cientifica propia, la formación de cualquier nivel se imparte desde Enfermería y la discusion científica tiene un enfoque paciente que, permitirá ofertar a la sociedad un producto exclusivo de las enfermeras que con el tiempo consolide una imagen social de profesionalización del cuidado en su vertiente científica.

¿Cómo es un programa de Doctorado? Con la legislación actual

Los programas de Doctorado regulados por el RD 99/2011, se acreditan por las agencias de evaluación de la calidad y son autorizados por el Ministerio de Educación y las Comunidades Autónomas. 
En este sentido, están sometidos a normas de calidad que los hacen muy competitivos. El pasado mes de Marzo, la Universitat Jaume I de Castellón obtuvo la primera acreditación que se concede en España a un Doctorado en Ciencias de la Enfermería regulado por el RD 99/2011, adquiriendo un importante compromiso con las Ciencias de la Enfermería.

Se trata de un programa descentralizado, con estructura de núcleos operativos, situados en Cataluña, Madrid, Andalucía, Aragón, Islas Canarias, Región de Murcia y la Comunidad Valenciana.

La investigación del programa va dirigida hacia las Enfermedades Crónicas y grupos específicos de población como las Personas mayores, Historia y Gestión Clinica.

El programa comenzará durante el curso 2013/2014. Para la admisión del estudiantado se requiere una formación previa de 120 ECTS de formación Máster de los que al menos 60 ECTS sean de investigación con independencia de que, la titulación de origen sea la Diplomatura o el Grado en Enfermería.

La elaboración y posterior defensa de la tesis doctoral se debe realizar durante 3 años para los estudiantes a tiempo completo o 5 para los estudiantes a tiempo parcial. Durante este periodo, el estudiantado, realizara actividades formativas que le sirvan de apoyo para su investigación.

En consecuencia, se trata de un programa descentralizado que permita realizar investigación reglada desde Enfermería para aportar a las personas que utilizan los sistemas sanitarios una mejora en la calidad de la atención. Igualmente contribuirá a la normalización científica de la profesión.

Dra. Loreto Maciá Soler. Vicedecana Facultad Ciencias de la Salud Universitat Jaume I 